\title{
Effect of Peer Collaboration Learning Strategy on Basic Science and Technology Students' Achievement in Nasarawa State, Nigeria
}

\author{
Aku Philip Eggon and P. A. Agu \\ Department of Science, Technology \& Mathematics Education, Faculty of Education, Nasarawa State University, \\ Keffi, Nigeria
}

E-mail: philipeggon@gmail.com; ashlameagu@yahoo.com

*Corresponding author details: Assoc. Prof. P.A. Agu, ashlameagu@yahoo.com

\begin{abstract}
This study examined the effect of peer collaboration learning strategy on Basic Science and technology students' achievement in Nasarawa state, Nigeria. The study employed non-equivalent group pre-test, post-test quasi experimental design. The population of the study was 638 upper basic school levels. A simple random sampling technique was used to sample 128 students from six co-educational schools within Lafia Local Government Area of Nasarawa State, Nigeria. Two research questions with two correspondent hypotheses guided the study. The instrument used for data collection was Basic Science and Technology Achievement Test (BSTAT) which was pilot tested using Kuder-Richardson (K-R, 20) formula to determine its reliability coefficient and this was found to be 0.99 . Descriptive statistics of means and standard deviations were used to answer the research questions and inferential statistics of Analysis of Covariance (ANCOVA) was used to test the hypotheses at 0.05 significant level. The results of the study showed that, Peer Collaboration Learning Strategy enhanced students' achievement in Basic Science better than Demonstration method. There was a significant difference between the mean achievement scores of students taught Basic Science using peer collaborative learning strategy and those taught using demonstration methods and there was no significant difference between the mean achievement scores of male and female students taught Basic Science and Technology using peer-collaborative learning strategy. The study, therefore, recommended among others that Basic Science and Technology teachers should not only use peer collaborative strategy to teach students the subject matter but should also allow them to interact with one another, so that the students can take charge of how they learn.
\end{abstract}

Keywords: Effect; peer collaboration; learning strategy; achievement; basic science and technology

\section{INTRODUCTION}

Science education plays a vital role in the lives of individuals and the development of a nation. It is widely and generally acknowledged that, the gateway to the survival of a nation scientifically and technologically is scientific literacy which can only be achieved through science education (Adaramola \& Obomunu, 2011). Nations all over the world, Nigeria inclusive, are striving to develop technologically and scientifically (Adejoh, Amali \& Omaga, 2013). This is only possible with good teaching and learning of science at the secondary school level. Ali (2004) observed that nations that are deemed to be developed and largely considered as civilized have achieved the status through purposeful and strategic scientific education of their citizens. Relatively, science educators have received national emphasis on the country's bid to achieve indigenous technological and industrial development through improved methodology (FRN, 2004).

As a result, national, state and private workshops and seminars have given rise to the development of science curriculum projects such as the Nigerian Primary Science Project (NPSP), the Nigerian Integrated Science Project (NISP) and the Nigerian Secondary School Science Project (NSSSP). Though, these projects are more than two decades ago, they seem to have not made appreciable impact on the teaching of science subjects in Nigeria. These have not only created a new awareness of science, but have also indicated the need for a radical departure from or modification of such conventional methods of teaching sciences such as inquiry methods modified to guided inquiry method. Basic Science and Technology educators are also in this quest, since there is need of more effective methods of teaching and learning of science. In view of the importance of science to national development, science education curriculum is developed at various levels of education in Nigeria. The science education courses at the Basic Education level include Basic Science and Technology at lower and middle Basic Education (primary1-6), Basic science at upper Basic Education (Junior Secondary School - Upper Basic1-3). At the senior secondary school level, the subjects include, Biology, Chemistry and Physics, while at the tertiary education level, the following courses are available; Biology education, physic education chemistry education and integrated science among others (Nigerian Educational Research and Development Council (NERDC, 2007). The Basic Science and Technology curriculum recently introduced is new in Nigerian schools, though the curriculum is a further enhancement of that of integrated science. Basic Science and Technology stresses to beginners the general principles which run through the entire world of science and technology. In effect, teachers who are trained to teach basic science and technology must move away from discriminatory attitude towards integrating all the elements of science and technology. This means that basic science and technology teachers must be 
competent in the subject matter so as to eliminate the boundaries and repetition from various sciences such as Biology, Chemistry, and Physics. The objectives of Basic Science and Technology curriculum include, developing students interest in science and technology so as to enable them acquire basic knowledge and skills in science and technology, to enable students to apply the scientific and technological knowledge and skills to meet societal needs, to enable students to take advantage of the numerous career opportunity offered in science and technology and to enable learners become prepared for further studies in science and technology (Nigerian Educational Research and Development Council, NERDC, 2007).

Basic science and Technology is the foundation of all sciences and technical subjects and those who pass it with a credit pass at Basic Education Certificate Examination/ Junior School Certificate Examination (BECE or JSCE) are qualified to read sciences and technical subjects at the Senior Secondary School level. This prepares them to advance to other higher and specific courses in science and technology at the tertiary institutions in Nigeria or foreign countries. Due to the important role Basic Science and Technology plays in the life of a nation and her citizenry, there have been repeated efforts that brought about the changes from Integrated Science at lower school level to Basic Science and Technology with a view to arriving at a curriculum that would satisfactorily meet the needs and aspirations of Nigerians, and as a result, there is need for innovative methods of instruction that are activity based strategy to improve students' achievement in Basic Science and Technology. Despite the relevance of basic science and technology as a foundation course for the sciences and national development, research report by Okebukola (2005), Ajagun (2006) and Adejoh (2012) working separately have lamented over the poor performance of science and technical students in Nigeria. According to Achor and Kalu (2014), the achievement of students in sciences in Nigeria has remained consistently poor. Infact, a survey of the achievement in Upper Basic School (UBS) Basic science and technology in Nigeria over the years reveals a discernable decline.

This phenomenon has remained a source of concern to science educators and Specifically Basic Science and Technology experts (Okeke, 2007). Anekwe (2008) attributed the problem to inappropriate teaching strategies and non-availability of necessary facilities for the teaching of sciences and technologies among other things, in addition to students' socio-economic background and intelligence. As a result, many students have failed to advance in science and technology at the senior secondary school due to their poor performance in the Basic Science and Technology subject at the Basic Education Certificate Examination (BECE) or Junior School Certificate Examination (JSCE). Those who scale through into the Senior Secondary Science class perform poorly at their Senior School Certificate Examination (SSCE) examinations due to their poor foundation at the Basic school level. This may occur as a result of inappropriate use of strategies by science teachers (Anekwe, 2008). The implementation of the National Policy on Education so far ought to have helped reduce this failure trend but there are several factors accounting for the decline in performance such as defective curricular, poor implementation, lack of provision of instructional materials and facilities, lack of manpower. Unfortunately, the trend appears to have continued as indicated by the various reports from Nasarawa State Examinations Boards (NSEB) from 2015-2019. The rate at which students pass Basic Science and Technology and Mathematics is low compared to other Arts subjects like Social studies, Creative art, Physical and Health Education within these years. The result of Basic Education Certificate Examination (BECE) has shown that students' achievement has persistently remained below 50 percent, the implication of this is that less than half of the students who sat for BECE/JSCE in basic science from 2015 to 2019 failed to obtain the prerequisite grades to qualify them for entry into science and technical oriented career at higher educational level. This issue of students' under-achievement in basic science has been persistently associated with the kind of instructional methods employed by the teachers and may also be as a result of some difficult concepts such as human systems and some aspects of physics related content in basic science. On the other hand, Nwosu, (2007), Okeke (2008) and Azuka (2009), have put the blame for the poor performance in basic science and technology in schools on; the classroom teacher; teacher's professional training in school and on the method of teaching employed. By and large, evidence of their research findings and day-to-day events appear to lay weight to the foregoing claims that teachers may be responsible for the under-achievement in science and technical education. Here, reference is often made to the methodologies used by the teachers. In the same vein, Nwosu (2007) pointed out that by using the conventional methods such as demonstration method, lecture method and discussion methods, the teacher talks most of the time while the students listen passively and watch as the teacher demonstrates and reads aloud the content. This makes the classroom learning environment teacher dominated, textbook bound and examination oriented without recognizing the need for the development of science process skills in the students. Science teaching must be done through appropriate strategies which foster understanding for applicability. Good quality teaching gives rise to functional learning (Jirgba, 2008). Studies by Zimmerman (2005), O'Donnell (2006), Poellhuber, Chiominneand Karsenti (2008) and Samuelson (2010) have revealed that learners' understanding of science concepts is often inadequate or erroneous due to poor methodology leading to nongrasping of concepts and obvious compartmentalization of scientifically valid ideas with the end result being rote learning.

Some scholars (Achor, Imoko \& Uloko, 2009) have asserted that methods of science instruction including the activity-based strategies seem to be ineffective in terms of students' achievements and require some modifications. In agreement with these assertions, science educators such as Adejoh, (2009); Samba and Eriba, (2012) have researched into method combination and modifications that can bring about effective teaching and learning of Basic Science which is the foundation of all sciences at the higher levels. Perhaps, an addition of method combinations such as peer collaboration and that form literature are scarce in the study area could make for the intended change. The researcher observed that peer learning as pedagogical strategy are usually not introduced to students of Basic Science at the Upper Basic School classes as the actual teaching method in Nasarawa State and perhaps, Nigeria at large.

Peer collaboration is a method in which 4 or more students work together face-to-face in a classroom setting towards achieving a mutual goal of learning from a particular task (O'Donnell, 2006). Generally, some scholars (Zimmerman, 2008; Samuelson, 2010) have suggested that peer collaboration is a more effective 
method of teaching science at the Junior Secondary School level. This has also been approved by many educational researchers for the past decade for its positive role in classroom-based learning, which has been evaluated positively in the outcome of learning among distance education learners. Poellhuber, Chiominne and Karseti (2008) opined that one way of enabling students to learn and understand science and the process of science is to teach science as peer collaboration and self-regulated learning strategies. Some science educators such as Keramati (2010) and Wayne (2013) have come up with different strategies all with the intention to improve teaching and learning of science such as guided enquiry, concept mapping and discovery.

Demonstration teaching method which means display of something or show others how it can be done during teaching and learning with example is a way of acquiring skills in science and technical subjects because during demonstration it shows how to carry out science process. In demonstration teaching methods, teachers utilize when materials to be used in teaching are dangerous or when the materials for teaching are inadequate. During demonstration teaching method, the students listen, observe and watch keenly and participate less. The teaching of Basic Science and Technology appears to have been reduced to a descriptive exercise through the use of conventional demonstration. Considering this kind of background, this researcher is of the view that, making students to be aware of their role in a collaborative classroom could have facilitative effect on learning while a teacher acts as a mediator or a facilitator. Samuelson (2010) observed that, most teachers emphasize demonstration method in teaching science rather than activity based strategies such as peer collaboration, constructivism and selfregulated aspect of teaching science and technical subjects.

Gender is another relevant issue in the learning of Science and Technology, since the social expectations that prescribe how males and females think, act and feel differs. In Nigeria, as in other countries of the world, Science and Technology are usually viewed as male dominant subjects (Ogunkunle, 2009). Girls opt for careers inhumanities and social science related careers. Gender differences in science achievement has been the major concern in science and technical education since educators seek to provide avenues for achieving gender equity for sustainable development. Student's performance in the science at both upper basic and senior secondary school levels of education varies across gender. It appears that female students are more scared of science subjects in which basic science and technology is inclusive at both levels and as a result fewer girls than boys who take the science subjects at the Senior School (SS) level perform poorer at the SSCE than their male counter-parts (Okeke, 2008). Studies comparing performance of boys and girls in the basic science shows that boys perform better than girls in science and technology (Aigbomian, 2006). Ogunkunle (2009) observed that boys perform better than girls in science, technical and mathematics in which Basic Science and Technology is inclusive when tests attempt to measure problem-solving skills at the complex cognitive level. The authors attributed the low achievement of girls to spatial ability and other cognitive disadvantages. On the other hand, Hyde and Mertzb (2009), observed that girls performed better than their male counterparts in science subjects. The thrust of this paper was to investigate the effect of peer collaboration learning strategy on students' achievement in Basic Science in Nasarawa State, Nigeria in relation to gender.

\section{OBJECTIVES}

The objective of this study was to ascertain the effects of peer collaboration learning strategy on Basic Science and Technology students' achievement in Nasarawa State. Specifically, to study sought to:

1. determine the effects of peer collaboration learning strategy on Basic Science students' achievement in Nasarawa State, Nigeria.

2. compare the mean achievement scores of male and female students using peer collaboration learning strategy in the study Area.

\section{RESEARCH QUESTIONS}

In order to provide direction and focus to the study, the following research questions guided the investigation:

1. What are the mean achievements scores of students taught Basic Science and Technology using Peer collaboration and those taught using demonstration methods in Nasarawa State, Nigeria?

2. What is the difference in the mean achievement scores of male and female students taught Basic Science and Technology with peer-collaborative learning strategy in Nasarawa State, Nigeria?

\section{HYPOTHESES}

The following hypotheses were formulated and tested at 0.05 level of significance:

1. There is no significant difference in the mean achievement scores of students taught basic science and technology using peer-collaborative learning strategy and those taught using demonstration methods in Nasarawa State, Nigeria.

2. There is no significant difference in the mean achievement scores of male and female students taught basic science and technology using peer collaboration learning strategy in Nasarawa State, Nigeria.

\section{METHODOLOGY}

The study employs quasi-experimental design. The two learning conditions are Peer Collaboration Verses (CV) Control and Demonstration Method (DM). The choice of this design was due to the fact that this study used intact classes because it was not feasible to adopt true experimental design as this would distort the academic programmes of the schools involved in the study due to randomization of subjects to experimental and control groups. The total population of this study consisted of 7,034 Upper Basic two students in 42 government grant aided secondary schools in Lafia Local Government Area of Nasarawa State, Nigeria. Simple random sampling techniques of hat draw method was used to sample 128 students from six coeducational secondary schools taken from the population of 638 students of grant aided schools. The instrument used for data collection in this paper was Basic Science and Technology Achievement Test (BSTAT). The researchers developed two forms of BSTAT, pre-test, post-test Basic Science and Technology Achievement Test (BSAT) for Upper Basic 2 (UB2). The instrument was made up of two parts namely, section (A) 
is the demographic information while section B consists of multiple choice test made up of initial 40 items. The BSTAT was administered twice, before (pre) and after (post) the experiment. The pre-BSTAT was used to ascertain the level of Basic Science and Technology academic achievement at which the students were before the treatment. The post-BSTAT was used to determine the extent of students Basic Science and Technology achievement after the treatment. The difference between the two forms of BSTAT was in the arrangement of item options and reshuffled serial numbering only. The topics chosen were from basic science and technology book 2 syllabuses/ curriculum. Two sets of lesson plans were developed by the researchers and used in teaching both the experimental and the control groups. All the students in the experimental group received training on peer collaborative learning strategy and after pre-test for two periods of lessons for 40 minutes each before taking part in the treatment except control group. Firstly, in PCLS after pre-test administration, presentation of text material to the students then instructions were given to them on how to go about the learning task. Both face and content validations were carried out in this study. The Basic Science and Technology Achievement Test (BSTAT), and lesson plans for the three strategies were validated by three experts in Science and Technical Education for assessment. Reliability index of 0.99 was obtained using Kuder-Richardson (K-R, 20). Descriptive statistics of Means and Standard Deviations were used to answer the research questions and inferential statistics of Analysis of Covariance (ANCOVA) was used to test the hypotheses at $0.05 \%$ level of significance

\section{RESULTS}

Data analysis and interpretation was done based on research questions and hypotheses and are presented in Tables 1 to 4:

Research Question 1: What are the mean achievements scores of students taught Basic Science and Technology using Peer collaboration and those taught using demonstration methods in Nasarawa State, Nigeria?

TABLE 1: Mean and Standard Deviation of Students' Scores in Peer Collaboration Learning and Demonstration Strategy Classes

\begin{tabular}{llccc}
\hline Group & & Pre-BSAT & Post-BSAT & Mean Gain \\
\hline $\begin{array}{l}\text { Peer Collaboration Learning } \\
\text { Strategy (PCLS) }\end{array}$ & & & \\
& Mean & 21.39 & 26.46 & 5.07 \\
& $\mathrm{~N}$ & 46 & 46 & \\
Demonstration Method (DM) & Std. Dev. & 4.63 & 5.11 & 4.51 \\
& Mean & 12.37 & 16.88 & \\
& $\mathrm{~N}$ & 41 & 4.66 & 0.56 \\
\hline
\end{tabular}

Table 1 reveals that students in Peer collaboration class had a mean gain of 5.07 while those in demonstration class had 4.51 with a mean difference of 0.56 in favour of Peer Collaboration Strategy class. This means that Peer Collaboration class received instruction and gained more compared to those in demonstration class. By implication, Peer Collaboration Strategy facilitated achievement more in Basic science and Technology compared to demonstration method that is popular and used regularly by the teachers. Therefore, Peer Collaboration Learning Strategy enhanced students' achievement in Basic Science and Technology better than Demonstration method.

Research Question 2: What is the difference in the mean achievement scores between male and female students taught basic science and technology with peer-collaborative learning strategy in Nasarawa State?

TABLE 2: Mean and Standard Deviation of Male and Female Students' Score in Peer-Collaboration Learning Class

\begin{tabular}{llccc}
\hline \multicolumn{1}{c}{ Gender } & & Pre-BSAT PCLS & Post-BAST PCLS & Mean Gain \\
\hline Male & Mean & 21.29 & 26.52 & 5.23 \\
& N & 21 & 21 & \\
Female & Std. Dev. & 5.35 & 5.48 & 4.92 \\
& Mean & 21.48 & 26.40 & \\
& N & 25 & 25 & 0.31 \\
\hline
\end{tabular}

Table 2 shows a mean gain of 5.23 for the male students in Peer-Collaboration Strategy class while the females in the same class had 4.92 with a mean difference of 0.31 in favour of the male students. This means that the male students received instruction and gained more in Peer- Collaboration class compared with the female students in the same class. By implication, Peer-Collaboration Strategy facilitated higher achievement among the male students in basic science 
and technology compared when with the female students in the same class. Therefore, Peer- Collaboration Strategy enhanced male students' achievement in basic science and technology better than that of female students.

\section{HYPOTHESES}

Ho1: There is no significant difference in the mean achievement scores of students taught basic science using peercollaborative learning strategy and those taught using demonstration method in Nasarawa State, Nigeria.

TABLE 3: ANCOVA Test of Effects of Peer-Collaboration Learning Strategy and Demonstration Method on Students' Achievement in Basic Science

\begin{tabular}{lccccc}
\hline \multicolumn{1}{c}{ Source } & Type III sum of Squares & df & Mean Square & F & Sig. \\
\hline Corrected Model & $2701.683 \mathrm{a}$ & 4 & 675.421 & 41.610 & .000 \\
Intercept & 568.246 & 1 & 568.246 & 35.008 & .000 \\
Pre-BSAT & 695.204 & 1 & 695.204 & 42.829 & .000 \\
Group & 130.074 & 1 & 130.074 & 8.013 & .006 \\
Error & 1331.029 & 82 & 16.232 & & \\
Total & 45921.000 & 87 & & & \\
Corrected Total & 4032.713 & 86 & & & \\
\hline
\end{tabular}

R Squared $=.670$ ( Adjusted R Squared $=.654$ )

Table 3 shows that with $\mathrm{df} @ 86, \mathrm{~F}=8.01, \mathrm{p}=0.01<0.05$, there is a significant difference between the mean achievement scores of students taught basic science and technology using peer collaborative learning strategy and those taught using demonstration methods. This means that the difference in mean between students in peer-collaboration Strategy class and those in demonstration method class in basic science and technology was significant. Thus the null hypothesis is rejected and it is therefore concluded that there is a significant difference between the mean achievement scores of students taught basic science using peer-collaborative learning strategy and those taught using demonstration method.

HO2: There is no significant difference in the mean achievement scores of male and female students taught basic science and technology using peer collaboration learning strategy in Nasarawa State, Nigeria.

TABLE 4: ANCOVA Test of Effects of Peer Collaboration Learning Strategy(PCLS) on Male and Female Students' Achievement in Basic Science

\begin{tabular}{lccccc}
\hline Source & Type III sum of Squares & df & Mean Square & F & Sig. \\
\hline Corrected Model & $287.685 a$ & 2 & 143.843 & 6.967 & .002 \\
Intercept & 439.317 & 1 & 439.317 & 21.280 & .000 \\
Pre-BSAT PCLS & 287.510 & 1 & 287.510 & 13.927 & .001 \\
Group & .603 & 1 & .603 & .029 & .865 \\
Error & 887.728 & 43 & 20.645 & & \\
Total & 33373.000 & 46 & & & \\
Corrected Total & 1175.413 & 45 & & & \\
\hline
\end{tabular}

R Squared $=.245$ ( Adjusted R Squared $=.210$ )

Table 4 shows that with $\mathrm{df} @ 45, \mathrm{~F}=0.029, \mathrm{p}=0.87>0.05$, there is no significant difference between the mean achievement scores of male and female students taught basic science and technology using peer-collaborative learning strategy. This means that the difference in mean between male and female students in peer-collaboration strategy class in basic science and technology was not statistically significant. Thus the null hypothesis was not rejected. It was therefore concluded that there is no significant difference between the mean achievement scores of male and female students taught basic science and technology using peer-collaborative learning strategy.

\section{DISCUSSION OF FINDINGS}

This study revealed that Peer-Collaboration Learning Strategy enhanced students' achievement in Basic Science and Technology better than Demonstration method. There was significant difference between the mean achievement scores of students' taught basic science and technology using peer-collaborative learning strategy and those taught using demonstration method. This finding is not in tandem with that of Davidson (2006), Winter (2009), Igboko and Ibeneme (2011) in the sense that, Davidson investigated the effects of collaborative learning method on achievement, retention and attitudes of Home Economics students in North Carolina and did not find collaborative learning to be more effective than traditional learning methods with regards to achievement and retention. Also, Winters (2009) found that there was no significant difference in the mean achievement scores of students who studied in peercollaborative group and those who studied individually.
The contradiction of the foregoing studies to the finding of the present study was not surprising as the effectiveness of peer collaboration learning strategy depends on its monitoring and time allowed. For instance, there are a number of factors that may be related to the success of peers engaged in unstructured collaborative learning. The first factor that may be related to success is students' perception that the task involves working with a peer to build a shared understanding. The second factor related to success may be the use of self-regulatory processes, while the third factor related to some prior knowledge of the topic and fourth factor is time it takes to learn the activity. There appear to be several individual differences for example, task perception, and ability to regulate learning processes and prior knowledge and contextual example. Time of task may be related to how successful students are when they engage in peer collaboration with task; and those students' prior academic experiences may play 
a crucial role in determining the individual factors that students bring to a peer collaborative activity.

Another finding from this study is that peer collaboration strategy is gender friendly as it gives both male and female opportunities to learn and achieve on a near equal basis. This finding is in agreement with that of Ibe (2008) who investigated the effect of instructional materials manipulation on breaking gender barriers on achievement of male and female students in Science, Technology and Mathematics Education at the University of Nigeria Nsukka. It was revealed that no significant difference exists between the mean achievement scores of boys and girls when exposed to each of the teaching methods, that is, guided inquiry and demonstration methods. The issue here is that when a method is interactive and engages male and female students, the differences in achievement due to gender tends to disappear. This result however is not in agreement with Akalonu (2008) who conducted a study on the use of female friendly curriculum materials on the achievement and interest of male and female upper basic I students. The outcome of the study showed that the achievement test scores of female students were higher than those of male students, mean test scores and the ANCOVA for the effect of treatment on achievement in integrated science revealed a significant gender difference. It is worthy of note however that the females did better than the males in Akalonu's study probably because female friendly curriculum was used for the study and this could be the reason for this exception.

\section{CONCLUSION}

The findings of this study have established that peer collaboration learning strategy is superior to demonstration learning method as it enhanced students' achievement in Basic science and Technology more than the demonstration method. Secondly, peer collaboration learning strategy proved to be non-discriminatory as it is gender friendly thereby enhancing achievement of both male and female students at near equal level.

\section{RECOMMENDATIONS}

Based on the above findings, the following recommendations were made:

1. Universal Basic Education commission UBEC at the local, state and federal levels should provide both adequate instructional and infrastructural resources for effective implementation of activities based teaching strategies such as the collaborative learning strategy in the teaching and learning of Basic Science and Technology.

2. The Federal Ministry of Education at the local levels, state levels, and federal should encourage the use of peer-collaborative learning strategy by sponsoring teachers to attend in-service training, seminars or workshops in order to acquaint them with this activity-oriented teaching strategy in learning of Basic Science and Technology in secondary schools.

\section{REFERENCES}

[1] Achor, E. E, Imoko, B.I. \& Uloko, E.S. (2009). Effect of ethno-mathematics teaching approach on Senior Secondary Students' achievement and retention in locus. Educational Research and Review, 4(8), 385-390. http://www.academicjournal. org/Enn.

[2] Achor, E. E. \& Kalu, R. U. (2014). Incorporating error analysis into the teaching of practical chemistry in senior secondary schools in Makurdi Nigeria: Any effect on achievement International Journal of Education and Practice, 2(2), 21-34. www.parkinsight.com

[3] Adejoh, M. J. (2012). Improving the quality of integrated science and introductory technology curricular in secondary schools. Nigerian Journal of Teacher Education and Teachin 4(1), 304-311.

[4] Adejoh, M. J, Amali, A. 0. \& Omaga, J. (2013). Improving the teaching and learning of basic science and technology through the use of instructional materials and improvisation. In M.O Nder, \& A. OAmali (Eds). Book of reading (22-29). Makurdi: Selfler Academic Press (SAP).

[5] Aigbomian, D. O. (2006). Science for All: Implication for the teacher and national development. 14th Inaugural Lectures of the Ambrose Ali University, Ekpoma, Edo State, Nigeria, Benin City: Ambik Press.

[6] Ajagun, G. A. (2006). Towards goods performance in school education. Nigeria Journals of Teachers Education and Teaching, 2(1), 117-125

[7] Akalonu, G. C. (2008). Using an instructional approach to break the gender barrier in Science, Technology and Mathematics Education. Owerri: Federal University of Technology, Owerri Publisher.

[8] Ali, A. (2004). Conducting research in education and the social science. Enugu: TashiwaNetworks Ltd.

[9] Anekwe, M.C (2008). Effectiveness of cooperative learning strategies on student interest in volumetric analysis at secondary school. Interdisciplinary Educational Journal, 1(2) 39-

[10] Azuka, B. F. (2009). Active learning in mathematics classrooms states. UBEB workshop manual for retaining of primary and JSS teachers on the implementation of new UBE curriculum and continuous assessment in schools. Abuja: Marvellous Mike Press Limited.

[11] Davidson, D. (2006). An overview of research on collaborative learning related to Home Economic. Journal of Educational Research 2(22) 362-365 North Carolina USA.

[12] Emaikwu, S. O (2013). Fundamental of Research Methods and Statistical Methods. Selfers Academic Press Limited

[13] Eriba, J. O. (2005). Teachers' Competence in Science Teaching. New Trends in Education, issues and challenges, (pp38-39), Book of reading. Faculty of Education, Benue State University, Makurdi.

[14] Hydea, J. S \& Mertzb, J. E. (2009). Gender, Culture and MathematicsPerformance;http:11tetvideo.madisan. com/uw/gender.

[15] Ibe, J. (2008). Effect of instructional material manipulation on breaking gender barriers on achievement of male and female students in Science, Technology, Mathematics Education (STME). Enugu: UNN Pub.

[16] Igboko, K. O. \& Ibeneme, O. T. (2011). Effect of collaboration/co-operative work on students' achievement and retention in Introductory Technology. Journal of Education, Federal University of Science and Technology Owerri, 3(1), 11-19. Jirgba, M.C. (2008). Attitude of science teachers towards the teaching of integrated science. Unpublished Masters Dissertation, Benue State University, Makurdi.

[17] Keramati, M. (2010). Effect of cooperative learning on academic achievement of physics course. Journal of Computers in Mathematics and Science. Technology 29(2), 155-173.NERDC (2007) Universal 
[18] Basic Education Commission (UBEC) a nine (9) year basic Education Curriculum Abuja: NERDC press

[19] Nwosu, A. A. (2007). Various Teaching Methods: An appraisal. In R.N.

[20] Amadi, A. D. Iwu \& Cnyemerekeya, C. (Eds.). Perspective in Teaching Practice: Avan. Global Publications

[21] O'Donnel, A. M. (2006). The Role of Peers and Group Learning. In P. Alexander \& P. Winne (Eds.) Handbook of Educational Psychology (2nd ed; pp.781-801). N.J Mahwah: Lawrence Erlbaum Associates.

[22] Ogunkule, R. A. (2009). Fostering gender equity in mathematics education for sustainable development. Journal of International Gender Studies, 4, 17-24.

[23] Okebukola, P. A. O. (2005). Teaching and Learning Integrated Science at the JSS Level. The state of art. Nigeria Education Forum, 12(1), 19-33.

[24] Okeke, E. A. C. (2008). Clarification and analysis of gender concepts Focus on research, Reproductive, Health education and gender sensitive classroom. Science teachers' association of Nigeria \& STME. Series 2:5

[25] Okeke, S (2007). Poor teaching method: The way forward. Onitsha: Nobel Graphite P.32-54

[26] Poellhuber, B., Chiominne, M. \& Karsenti, F. T. (2008). Effect of peer collaboration and collaborative learning on self-efficacy and persistence in a LearnerPaced Continuous intake model. London: England
[27] Samba, R.M.O. \& Eriba, J.O (2012). Innovative approaches in teaching different science concepts. Makurdi:

[28] Destiny, V. \&. Samuelson, J. (2010). The effect of peer collaboration on children's arithmetic and selfregulated learning skills. Sweden: Linkoping University press.

[29] Winters, F.I. (2009). Peer Collaboration: The role of questions and regulatory processes in conceptualknowledge learning. USA: Maryland.

[30] Wayne, S. (2013) The effect of cooperative learning on the academic achievement of social studies unpublished project submitted to the faculty of the evergreen

statecollege.http//archivies,evergreen.edu/mastersth ese/accession8910MIT/Stauffer

[31] Zimmerman, B. J. (2006). Developing self-fulfilling cycles of academic regulation: an analysis of exemplary instructional models. In D.H. Schunk \& B.J., Zimmerman (Eds). Self-regulated learning: From teaching to self-reflective practice(pp.1-19). New York: Guilford Press.

[32] Zimmerman, B. J. (2008). Investigating self-regulation and motivation: istorical background, methodological developments, and future prospects. American Educational Research Journal,45(1), 166-183. 